\title{
Variations in Typhoon Landfalls over China
}

\author{
Emily A. FOGARTY*1, James B. ELSNER ${ }^{1}$, Thomas H. JAGGER ${ }^{1}$, \\ Kam-biu LIU ${ }^{2}$, and Kin-sheun $\mathrm{LOUIE}^{3}$ \\ ${ }^{1}$ Department of Geography, The Florida State University, Tallahassee, Florida \\ ${ }^{2}$ Department of Anthropology and Geography, The Louisiana State University \\ ${ }^{3}$ Department of Public and Social Administration, City University of Hong Kong
}

(Received 27 April 2005; revised 9 February 2006)

\begin{abstract}
The interannual variability in typhoon landfalls over China is investigated using historical and modern records. For the purpose of substantiating and elaborating upon the claim of north to south variation in tropical cyclone activity over China, a north-to-south anti-correlation in yearly activity is confirmed in the historical cyclone records. When cyclone activity over the province of Guangdong is high (low), it tends to be low (high) over the province of Fujian. A similar spatial variation is identified in the modern records using a factor analysis model, which delineates typhoon activity over the southern provinces of Guangdong and Hainan from the activity over the northern provinces of Fujian, Taiwan, Zhejiang, Shanghai, Jiangsu, and Shandong. A landfall index of typhoon activity representing the degree to which each year follows this pattern of activity is used to identify correlated climate variables. A useful statistical regression model that includes sea-level pressure differences between Mongolia and western China and sea-surface temperature (SST) over the northwestern Pacific Ocean during the summer explains $26 \%$ of the interannual variability of the landfall index. It is suggested that a stronger than normal north-south pressure gradient increases the surface easterly wind flow over northern China; this, coupled with lower SST over the Pacific, favors typhoons taking a more westerly track toward southern China.
\end{abstract}

Key words: typhoons, southern China, historical record, climate variables

doi: $10.1007 / \mathrm{s} 00376-006-0665-2$

\section{Introduction}

Typhoons are among the most destructive of all natural disasters. When Typhoon Wanda hit Hong Kong in 1962, damage and casualties were widespread, 130 people were killed and at least 53 went missing. More recently, in 2003, Typhoon Nepartak brought torrential rains and strong winds to the west coast of Hainan causing 197 million dollars (US) in economic losses. More than 1.7 million people were affected and 800 homes were destroyed (China Daily, 2003). The economic loss in China from typhoon-generated storm surge averaged over the three costliest events since 1990 amounts to 2.7 billion USD (Kentang, 2000). Understanding the nature and causes of variability in tropical cyclone activity over China is an important step toward improving risk assessment.

A tropical cyclone is a warm-core non-frontal synoptic-scale cyclone, originating over tropical or subtropical waters, with organized deep convection and a closed surface wind circulation about a well-defined center. Typhoons are tropical cyclones of the western North Pacific (WNP) that have maximum sustained one-minute averaged wind speeds of $33 \mathrm{~m} \mathrm{~s}^{-1}$ or greater. Tropical storms are tropical cyclones having winds between $17 \mathrm{~m} \mathrm{~s}^{-1}$ and $32 \mathrm{~m} \mathrm{~s}^{-1}$. Numerous climate studies of typhoon activity are available $(\mathrm{Wu}$ and Lau, 1992; Lander, 1994; Chan, 1994; Chan and Shi, 1996, 2000; Lander and Guard, 1998; Chan et al., 1998; Chen et al., 1998; Wang and Chan, 2002). These studies focus mostly on factors affecting the variability in overall tropical cyclone activity. In general, tropical cyclones form over the warm ocean where sea surface temperatures (SST) exceed $26.5^{\circ} \mathrm{C}$. While a necessary condition, warm ocean waters are far from being sufficient for typhoon formation. Additional environmental conditions include weak vertical wind shear, thermodynamic instability and middle troposphere moisture (Gray, 1968, 1979; Emanuel, 1988; Molinari and Vollaro, 1989; DeMaria et al., 2001). Large-scale atmospheric and oceanic factors also play a role in modulating typhoon activity.

*E-mail: eaf1217@garnet.fsu.edu 
The earliest historical records of tropical cyclones are from China, where the documented history spans about 3500 years. The record length and the quality of these historical data vary from region to region. Yet, from an early period, the Chinese were aware of the essential features of typhoons, including their attendant storm surges. Meticulous records document the frequency of tropical cyclone landfalls over parts of China (Louie and Liu, 2003). In particular, the availability of records from two provinces in China (Chan and Shi, 2000; Liu et al., 2003) provides a unique opportunity to compare patterns of typhoon landfall activity across the centuries. Records of tropical cyclone activity from the second half of the 20th century follow from advances in satellite and aircraft reconnaissance. The most reliable data period begins in the mid-1960s with the advent of satellites. However, since we are concerned with landfall data, we use data back to 1945 . These modern records support a spatially more comprehensive analysis of typhoon activity in China, but they are temporally more limited. Thus in the present work we make use of both the historical and modern records of typhoon landfalls to better understand coastal typhoon variability.

From modern records we know that approximately one third of all tropical cyclones originate over the WNP, making it the most prolific of the tropical cyclone basins. The WNP basin supports the development of tropical cyclones year round, however the active season extends from May through November with a peak in late August or early September. The modern record, from 1945-2003, indicates that on average 28 tropical cyclones occur in the WNP each year. Approximately $61 \%$ of these become typhoons. Most WNP tropical cyclones track west-northwestward at low latitudes (i.e., $15^{\circ} \mathrm{N}$ latitude or lower). Approximately one-third continue on a west-northwestward track and make landfall in East Asia south of about $25^{\circ} \mathrm{N}$ latitude. A larger portion of the remaining twothirds turn northward, gain latitude, and eventually turn eastward as they enter the higher latitude westerly winds (Lander, 1996).

Variations in typhoon activity have been related to various climate patterns. During El Niño events, when SSTs in the central and eastern equatorial Pacific are higher than normal, tropical cyclones are relatively more likely to form east of about $160^{\circ} \mathrm{E}$ longitude (Lander, 1994). According to Chan (1985) typhoons tend to form farther east during El Niño events and are consequently more likely to remain east of China. The corollary is that typhoons are relatively more likely to effect China during La Niña years (Saunders et al., 2000). This ENSO-typhoon relationship is supported by an analysis of historical and modern data in Elsner and Liu (2003). Moreover, Wu et al. (2004) found a significant relationship between late season landfalls over China and ENSO and Ho et al. (2004) inferred that changes in typhoon tracks are associated with the westward expansion of the subtropical northwestern Pacific high.

From the above studies there is a clear consensus among researchers that large scale climate patterns affect tropical cyclone genesis regions and subsequent tracking. However, agreement has not been reached on how large-scale circulation patterns influence typhoon landfall variability. Here we address this question directly. More specifically, in this study we are interested in examining the case for a north-south anti-correlation in typhoon activity along the coast of China. This interest is prompted by the work of Liu et al. (2003) who speculated an inverse relationship across latitudes between the frequency of typhoons occurring over northern China to those occurring over Guangdong Province in the south (Liu et al., 2003). A similar anti-correlation across latitudes in U.S. hurricane frequency was noted and discussed in Elsner et al. (2000).

We begin with an examination of the historical record using correlation and log-linear regression analyzes. Results verify a north-south variation in cyclone activity. The modern record is subsequently analyzed to examine this variation in greater spatial detail. In this regard, we employ a factor analysis model. Output from the model is then used to study possible climate factors that might influence this variation. Data sources and methods are described in section 2 . In section 3 we verify the inverse relationship between tropical cyclone landfall frequency over Guangdong and Fujian. In section 4 we describe the factor analysis procedure applied to the modern typhoon counts including a test of the statistical significance of the results. A generalized least-squares regression of the factor scores onto the relative typhoon frequencies provides a landfall index. Section 5 examines climate patterns that are correlated with the landfall index. A summary and conclusions are given in section 6 . The originality of this work centers on the examination of both historical and modern landfall records and in the use of a factor model for identifying the dominant pattern of spatial variability in typhoon landfalls.

\section{Data Description}

What causes variations in the frequency of typhoons over China? In order to describe and model the spatial variability in typhoons, this study makes use of both modern and historical typhoon records and modern atmospheric data obtained from the National Centers for Environmental Prediction/National Center for Atmospheric Research (NCEP/NCAR) reanalysis project. The area examined is the WNP extending to the Chinese coastal provinces of Guang- 
dong (including Hong Kong), Fujian, Zhejiang, Shanghai, Jiangsu, and Shandong, including the islands of Hainan and Taiwan (Fig. 1). In this section we describe the historical and modern data sources and provide a brief description of the analysis methods.

\subsection{Historical Typhoons over Guangdong and Fujian Province}

The historical tropical cyclone data used in this study are obtained from Liu et al. (2003). According to their study, records of past typhoon activity are available in two groups of Chinese historical documents. First, ever since the Northern Song Dynasty (AD 960-1126), the Chinese government has kept a continuous record of typhoon strikes reported by local administrative authorities (Louie and Liu, 2003; Liu et al., 2003). The second source comes from local gazettes. These gazettes were written or last updated during the 19th and 20th centuries, although some date back as early as the mid 16th century (Louie and Liu, 2003). According to Louie and Liu (2003), the gazettes contain a catalog of major cultural and natural events, including typhoon strikes. Annual counts of typhoons affecting Guangdong Province for the years 1000-1909 were made available as were counts affecting Fujian Province for the years 1000-1920. It is likely that counts are underestimated prior to 1600 and that storms much weaker than typhoon intensity may not have been recorded. On the other hand, weaker storms causing considerable damage could have been recorded as typhoons. Here we use the word "tropical cyclone" to denote events in the historical list. We consider only the common years of 1600-1909 (310 consecutive years) for the present analysis. The reliability of the count data are likely not uniform over this 300 -year period. Societal development and the state of the science makes it likely that the early counts are less reliable than later counts. Since our focus here is on interannual variability, this trend in increasing reliability is not likely to significantly affect our results.

Figure 2 shows time series plots of the annual tropical cyclone counts for both Guangdong and Fujian. While we analyze the time series separately, it is likely that some tropical cyclones are counted in both provinces. Collectively there are 539 cyclones. This equates to an average rate of 1.7 tropical cyclones per year. Guangdong experiences considerably more storms compared with Fujian, with an average rate of 1.5 tropical cyclones per year and a maximum of 13 cyclones in a single year. This compares to an average rate of 0.2 per year and a maximum of 2 in a single year for Fujian. In this study we are interested in the co-variability of tropical cyclone landfalls across the two provinces.

\subsection{Modern Typhoon Records}

The modern typhoon record consists of 6-hourly positions (latitude and longitude in tenths of a degree) and intensities (5 kt intervals of maximum sustained (1-minute average) wind speed) for all western North Pacific tropical cyclones. The values are based on the Annual Tropical Cyclone Reports issued by the Joint Typhoon Warning Center (JTWC) in Hawaii. Extracted from these records is an annual count of tropical cyclones that made landfall over the period 1945-2003 between the months of May to November.

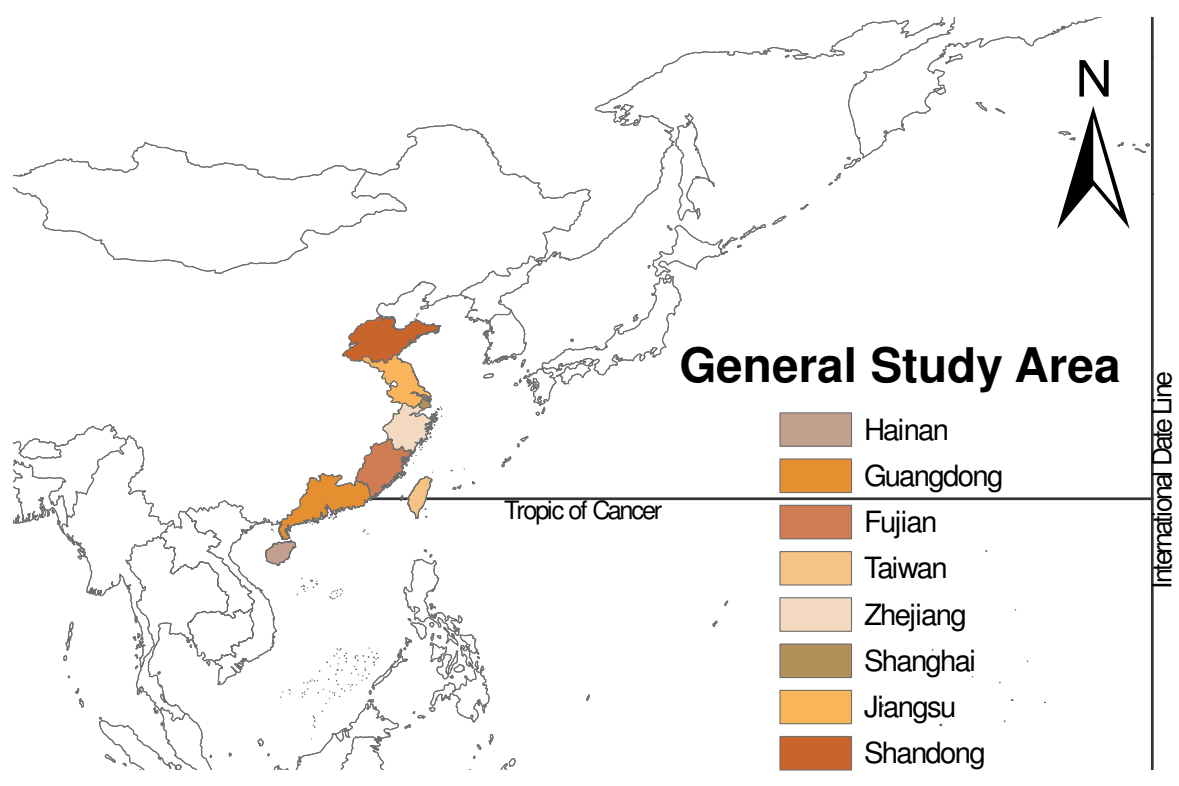

Fig. 1. The western North Pacific (WNP) tropical cyclone basin. The coastal provinces of China considered in this study are labeled. 

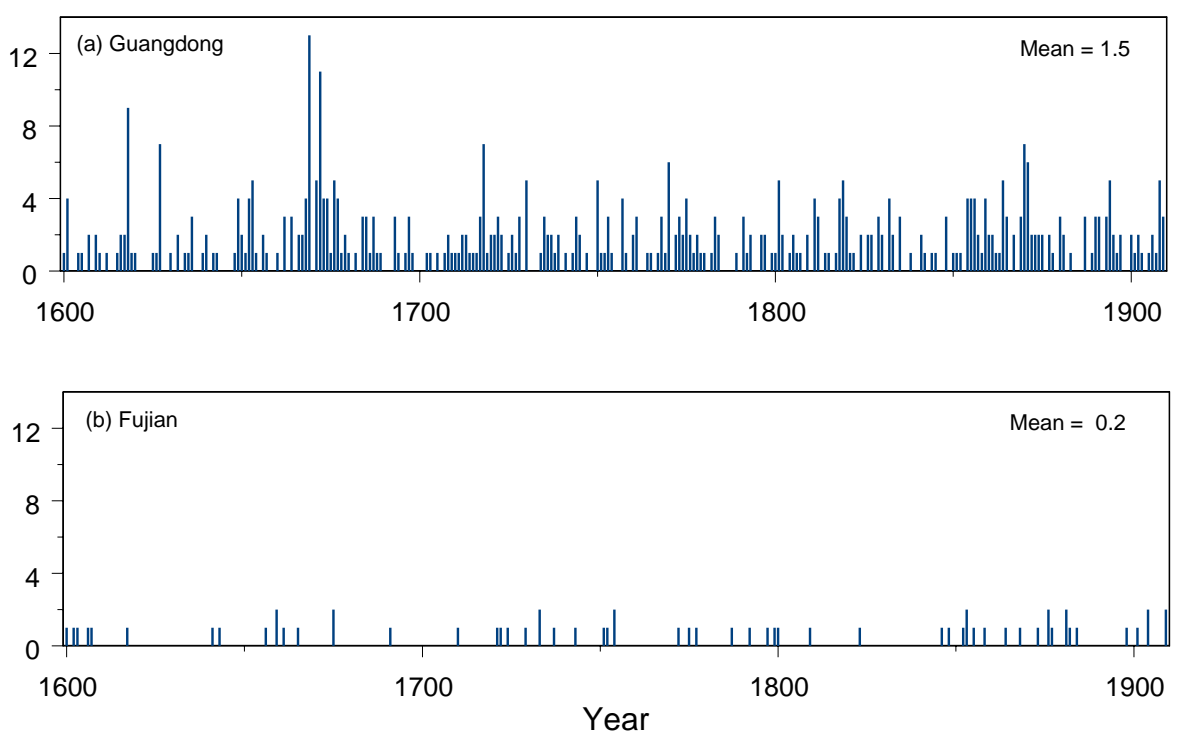

Fig. 2. Annual counts of Guangdong and Fujian Province typhoons for the years 1600-1909. The counts were extracted from historical documents (see Louie and Liu, 2003).

Landfalls are counted by coastal provinces including Guangdong (with Hong Kong), Fujian, Zhejiang, Shanghai, Jiangsu, and Shandong, including the islands of Hainan and Taiwan.

For each province, a count is added to the annual total if a storm reached typhoon intensity $\left(33 \mathrm{~m} \mathrm{~s}^{-1}\right)$ somewhere over the WNP and subsequently made a direct passage through the province. In this way, more than one province may count a single storm. Also, the storm is counted even if the winds at the time of passage through the province are less than typhoon intensity. Direct passage is defined as the straight-line path connecting 6 -h positions of the storm's circulation center. Counts are determined with the help of a geographic information system. A total basin-wide count of the number of typhoons is also used in the analysis to compute relative frequencies. The WNP basin extends from the international dateline to Asia.

These data show that $61 \%$ of all WNP tropical cyclones reached typhoon intensity. Furthermore, out of the 963 tropical cyclones that formed, 405 (42\%) made landfall over at least one of China's coastal provinces including the islands of Hong Kong, Taiwan and Hainan. Guangdong sees the most storms with an average annual rate of 1.8 per year. Its neighbor to the north has an annual rate of 1.2 per year which compares with 1.3 per year for Hainan and 1.4 per year for Taiwan. The northern provinces have fewer typhoons. The average annual rate for Zhejiang is 0.6. This compares with $0.1,0.2$, and 0.1 for Shanghai, Jiangsu, and Shandong, respectively. The annual counts are plotted as time series in Fig. 3. Here we see the large interannual variations in counts. Before modeling these data we change the annual counts to relative frequencies based on the total number of storms occurring over the WNP basin. Here we compare rates between modern and historical storms. The Guangdong records show 1.5 per year in the historical record compared to 1.8 in the modern record . These rates are comparable suggesting historical tropical cyclone counts are most likely records of typhoons not tropical cyclones. In fact since the historical rate is lower it may be that historical records consist of somewhat stronger typhoons. Similarly, the Fujian modern records indicate more typhoons, implying that the Fujian historical records report strong typhoons rather than weaker tropical storms.

\subsection{ENSO and the PDO}

Two large-scale atmospheric/oceanic index variables are used in the study to investigate possible relationships to the pattern of Chinese typhoons. The El Niño-Southern Oscillation (ENSO) refers to systematic variations of the ocean and atmosphere characterized by SST and sea-level pressure (SLP) changes in the tropical Pacific Ocean. El Niño is the warm oceanic phase, which is characterized by anomalously warm SSTs in the eastern and central tropical Pacific. The opposite phase, La Niña, is characterized by anomalously cool SSTs in the same region. The atmospheric component of ENSO is characterized by a zonal SLP variation called the Southern Oscillation. The Southern Oscillation Index (SOI) represents the difference in SLPs between Tahiti and Darwin, Australia.

Early works on variations in typhoon activity over 

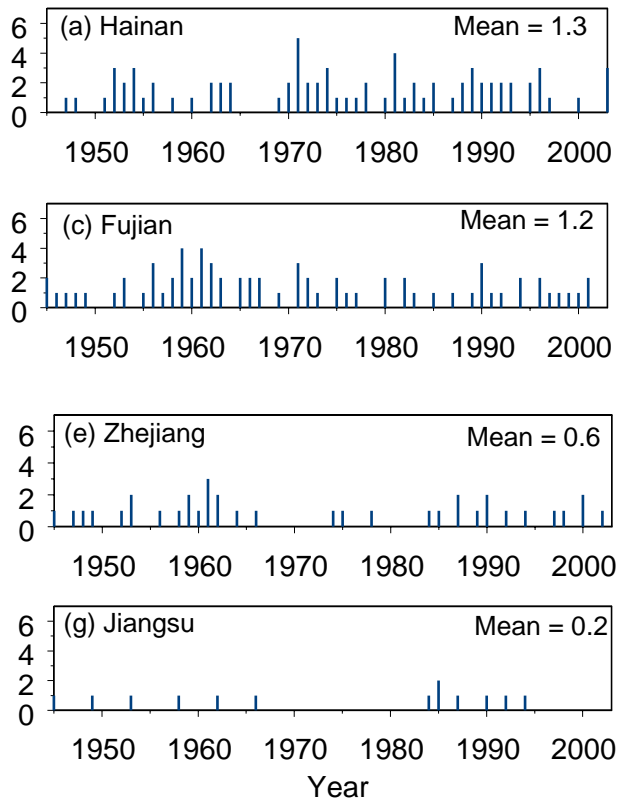
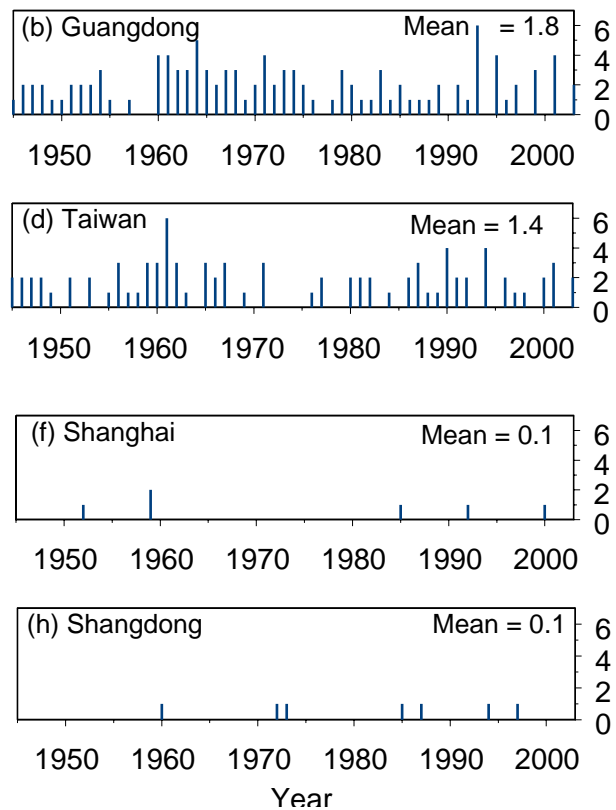

Fig. 3. Annual counts of typhoons over the period $1945-2003$ by coastal provinces. The counts are extracted from the modern records using a geographic information system (GIS). Storms that reached typhoon intensity and subsequently went on to strike China (not necessarily at typhoon intensity) are counted by determining an intersection of the track with the province outline. Storms striking more than one province are counted once for each province.

the WNP have indicated a relationship with ENSO. During El Niño conditions, tropical cyclone formation tends to shift farther to the east (Lander, 1994) and the cyclone's subsequent tracks tend to be toward higher latitudes (Elsner and Liu, 2003), thus we speculate that variations in the SOI will correlate with the typhoon landfall pattern. Monthly values of the SOI are obtained from the NOAA-CIRES (National Oceanic and Atmospheric Administration-Cooperative Institute for Research in Environmental Sciences) Climate Diagnostics Center (CDC), Boulder, Colorado, from their website at http://www.cdc.noaa.gov/. The Pacific decadal oscillation $(\mathrm{PDO})$ is a persistent atmospheric pressure pattern over the North Pacific Ocean with energy variations on the decadal timescale. It is the dominant factor in monthly SST variability in the North Pacific (north of about $20^{\circ} \mathrm{N}$ latitude) (Mantua et al., 1997). A PDO index (PDOI) is defined as the leading principal component of North Pacific monthly SST variability (poleward of $20^{\circ} \mathrm{N}$ latitude). The warm phase of the PDO (positive values of the PDOI) is characterized by negative SSTs and positive SLPs in the North Pacific.

\subsection{SLP and $S S T$}

Additional atmospheric and oceanic data are used in this study to investigate possible relationships to the pattern of Chinese typhoons not explained by ENSO or the PDO. The National Centers for NCEP/NCAR reanalysis data are available from the $\mathrm{CDC}$. The data are the result of a data assimilation using observational data from 1948 to the present and a fixed version of a numerical forecast model. The data are divided into six categories including pressure level, surface, surface flux, other flux, tropopause level and sigma level (Kalnay et al., 1996). The present study utilizes two first-order variables from the dataset. The first variable is SLP. We are interested in the largescale atmospheric surface pressure patterns across Asia and the Pacific that might influence the pattern of typhoons over China. Monthly data are averaged over the months of May through November. The second variable is SST over the middle latitudes of the northwestern Pacific Ocean. These data are examined in order to ascertain whether or not anomalous SSTs are related to tropical cyclone steering mechanisms and thus to the pattern of landfalls over China. The region chosen is $30^{\circ} \mathrm{N}$ to $60^{\circ} \mathrm{N}$ and $150^{\circ} \mathrm{E}$ to $180^{\circ} \mathrm{W}$ and the time period is June through August.

\section{Historical Tropical Cyclone Counts: Guang- dong versus Fujian}

We begin the analysis with an examination of the historical record. The counts of tropical cyclones affecting Guangdong and Fujian over the period 16001909 provide a long record for examining co-variability 
between these two regions (Fig. 2). Years of aboveaverage activity over Guangdong are out of phase with years of above-average activity over Fujian. The Pearson correlation coefficient verifies this with a value of -0.35 . Assuming that tropical cyclone activity in one year does not influence TC activity in the next year, the approximate $95 \%$ significance level is -0.11 . Thus we find a significant negative correlation (anticorrelation) between historical tropical cyclone counts over Guangdong and Fujian.

Although the Pearson correlation provides a quantitative estimate of this anti-correlation, its magnitude is sensitive to temporal trends. To control for long term trends in the data (real or observational), we examine the relationship using a regression model. The arrival of tropical cyclones on the coast can be considered a Poisson process (Elsner et al., 2001; Solow and Moore, 2000; Parisi and Lund, 2000; Elsner and Kara, 1999; Bove et al., 1998). The Poisson log-linear regression is a generalized linear model (glm) in which the mean of a response variable is related to explanatory variables through a regression equation. Here we use the glm to regress the annual Guangdong tropical cyclone counts on the year and annual Fujian cyclone counts. Analogous to the residual sum of squares in ordinary linear regression, the goodness of fit for a glm is measured by the (scaled) deviance. The deviance is a measure of the discrepancy between observed and fitted values. It serves as a generalization of the usual residual sum of squares for non-normal data. The mag- nitude of the drop in scaled deviance upon adding $\mathrm{Fu}-$ jian counts to the model that includes the year as a predictor is significant assuming a $\chi^{2}$ approximation with a $p$-value of 0.002 . Thus, even after accounting for the possibility of trends in the data, annual counts of Guangdong cyclones are significantly inversely related to those over Fujian.

Another way to see this inverse relationship is with conditional probability. A conditional probability is the probability of an event given the occurrence of some other event. For instance, the conditional probability of a Guangdong tropical cyclone will be higher given that Fujian is spared. Here we estimate the annual mean number of tropical cyclones over Guangdong when there are no Fujian cyclones, then we use the mean number as the annual rate parameter in a Poisson distribution to generate the probability distribution of Guangdong cyclones. We do the same for years in which there are at least one Fujian tropical cyclone. The probability distributions are compared in Fig. 4. Here we see that the probability of an active year over Guangdong (more than 3 ) is higher when Fujian receives no cyclones. Having established an anti-correlation in landfall activity between Guangdong and Fujian using historical documentary records, we are next interested in examining whether or not such an inverse relationship exists in the modern instrumental records. Here we have access to typhoon landfall counts all along the coast so we take a somewhat different approach.

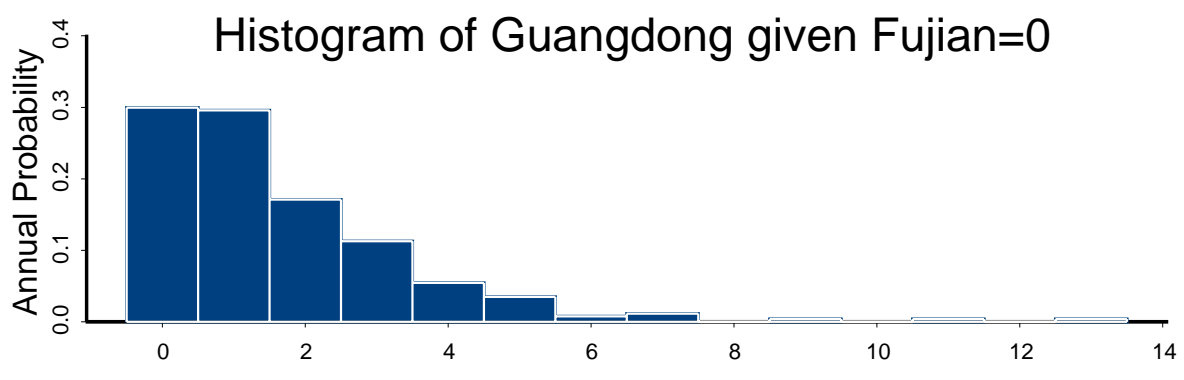

Histogram of Guangdong given Fujian $>0$

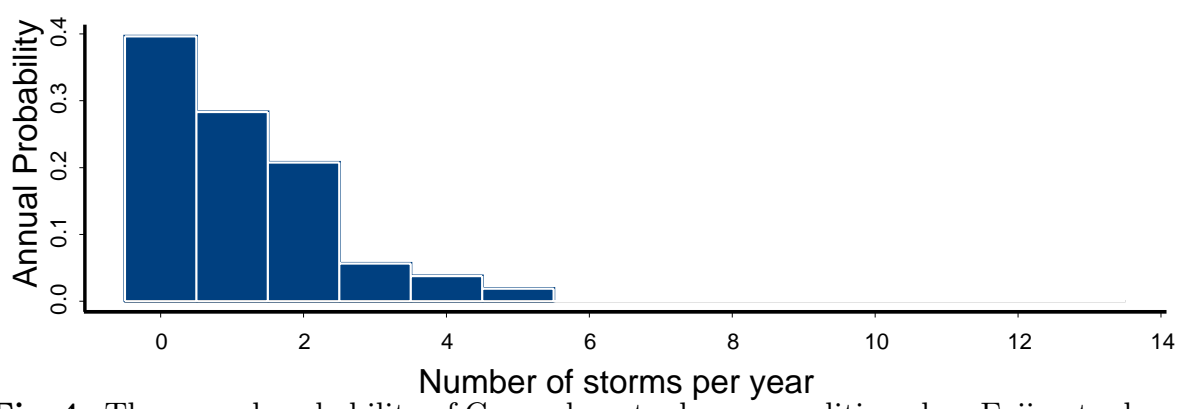

Fig. 4. The annual probability of Guangdong typhoons conditioned on Fujian typhoon activity. (a) The probability of a Guangdong typhoon in years without a Fujian typhoon. (b) The probability of a Guangdong typhoon in years with at least one Fujian typhoon. 


\section{Modern Typhoon Counts: A Landfall Index}

Typhoons typically form and track westward toward China; as they approach the coast they sometimes curve northwestward steering clear of China. On average, direct hits on the northern provinces are less likely than hits on the southern provinces as the northern coastline juts to the northwest. To lessen the effect this disparity in counts might have on our analysis, we combine the counts from Shanghai, Jiangsu, and Shandong. Figure 5 shows the annual typhoon rates in the the six regions, including the combined northern provinces which are labeled as SJS.

To normalize the annual counts we use relative frequency, where the relative frequency of a tropical cyclone is calculated by dividing the annual count by the total number of typhoons to occur in the WNP basin for the entire season. Relative frequencies are obtained for the 6 coastal regions. Correlations in annual frequencies between each of the regions is shown in Table 1. The matrix of values (correlation matrix) is in order from south to north, with Hainan southernmost and the region of SJS northernmost. On balance, the correlations are positive indicating that when activity is high (low) in one province it tends to be high (low) in the others. The exception is Guangdong and Hainan. When typhoon activity is high over the south it tends to be lower over the north. Interestingly, the cutoff between negative and positive correlation occurs between the provinces of Guangdong and Fujian. Next we employ a factor analysis model as a way to describe and quantify this overall pattern in annual typhoon frequencies.

\subsection{Factor Analysis Model}

A factor analysis model attempts to approximate

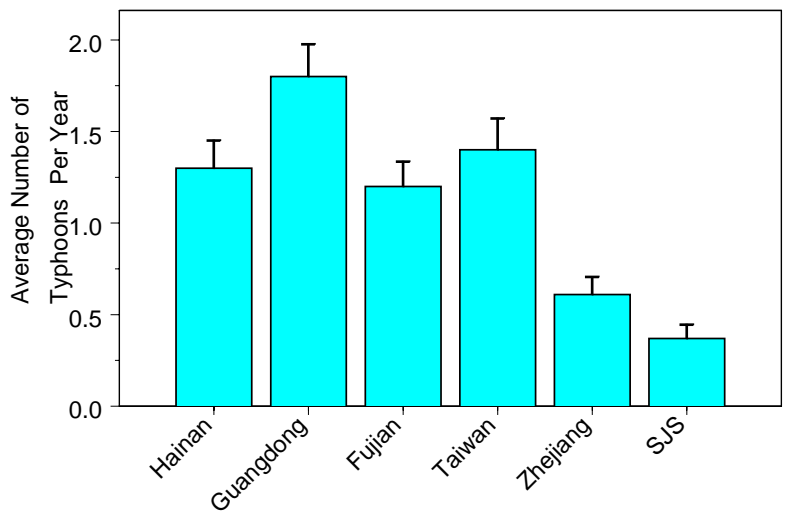

Fig. 5. The average annual count (rate) of tropical cyclones affecting coastal provinces of China. The rates are obtained by counting storms that made direct passage over the province. The period of record extends over 19452003. Whisker length on the bars indicates the magnitude of the standard error. the correlation matrix, with the object being to decide whether the data are consistent with a prescribed structure. Factor analysis is used to study patterns of relationships among dependent variables. The purpose of a factor analysis model is to describe, if possible, covariance relationships among the variables in terms of a few underlying, but unobservable, random quantities called factors. Factors that contribute to the correlation structure observed in the correlation matrix are the dependent variables being observed. The single factor model is composed of a response vector $\boldsymbol{R}$ that is equal to the single vector of factor loadings $\boldsymbol{F}$ times the factor scores $(s)$ plus an error vector $(\boldsymbol{e})$. The factor model formula is $\boldsymbol{R}=\boldsymbol{F} \cdot s+\boldsymbol{e}$, where the random variable $s$ has mean 0 and variance 1. The errors $\boldsymbol{e}$ form a random vector with uncorrelated components that are also uncorrelated with $s$, having mean 0 and variance less than 1 . The response vector $\boldsymbol{R}$ is the centered and scaled proportion term. The expected value of $\boldsymbol{R}$ is zero and the variance is equal to the transpose of the single vector factor loadings $\boldsymbol{F}$ times $\boldsymbol{F}$ plus the diagonal of the variances, $\operatorname{Var}(\boldsymbol{R})=\boldsymbol{F}^{T} \cdot \boldsymbol{F}+\operatorname{diag}\left(\sigma^{2}\right)$. The factor loadings are estimated using maximum likelihood methods. Once factor loadings are determined, factor scores are estimated using generalized least squares, fitting the response $\boldsymbol{R}$ using the inverse of the uniqueness as weights with the factor loadings as the predictors. The dependent variables are the annual typhoon frequencies in the 6 regions of coastal China.

Since we are only concerned with defining the leading factor, we use a one-factor model. Model solutions are the same whether we use a principal component or maximum likelihood method. The resulting factor loadings are plotted in Fig. 6. As expected, they show a north-south split with opposite signs on the loadings for Guangdong and Hainan compared to $\mathrm{Fu}-$ jian, Taiwan, Zhejiang and SJS. The split occurs between Guangdong and Fujian. Thus the factor analysis model appears to capture the main correlation structure of annual typhoon activity along the Chinese coast, and the results are consistent with the inverse relationship noted in the historical counts.

The magnitude of the factor score represents the degree to which the year represents the dominate covariability in relative typhoon frequencies. We call the time series of the 59 factor scores the landfall index (LI), as it represents the important variation in typhoon landfalls. A plot of the LI is shown in Fig. 7. Positive values of the LI indicate a propensity for storms to recurve and track north of the Tropic of Cancer, whereas negative values of the LI indicate the opposite effect with a larger proportion of landfalls occurring south of the Tropic of Cancer. Plots showing the tracks of typhoons during the year with the maximum (minimum) value of the LI are also shown in Fig. 7. Thus it appears that the factor model as summar- 
Table 1. Matrix of correlations in annual typhoon frequencies.

\begin{tabular}{lllllll}
\hline & Hainan & Guangdong & Fujian & Taiwan & Zhejiang & SJS \\
\hline Hainan & 1.000 & 0.139 & -0.268 & -0.274 & -0.197 & -0.143 \\
Guangdong & & 1.000 & -0.190 & -0.348 & -0.357 & -0.296 \\
Fujian & & 1.000 & 0.595 & 0.436 & 0.350 \\
Taiwan & & & & 1.000 & 0.386 & 0.158 \\
Zhejiang & & & & & 1.000 & 0.523 \\
SJS & & & & & & 1.000 \\
\hline
\end{tabular}

Note: SJS represents Shanghai, Jiangsu, and Shandong.

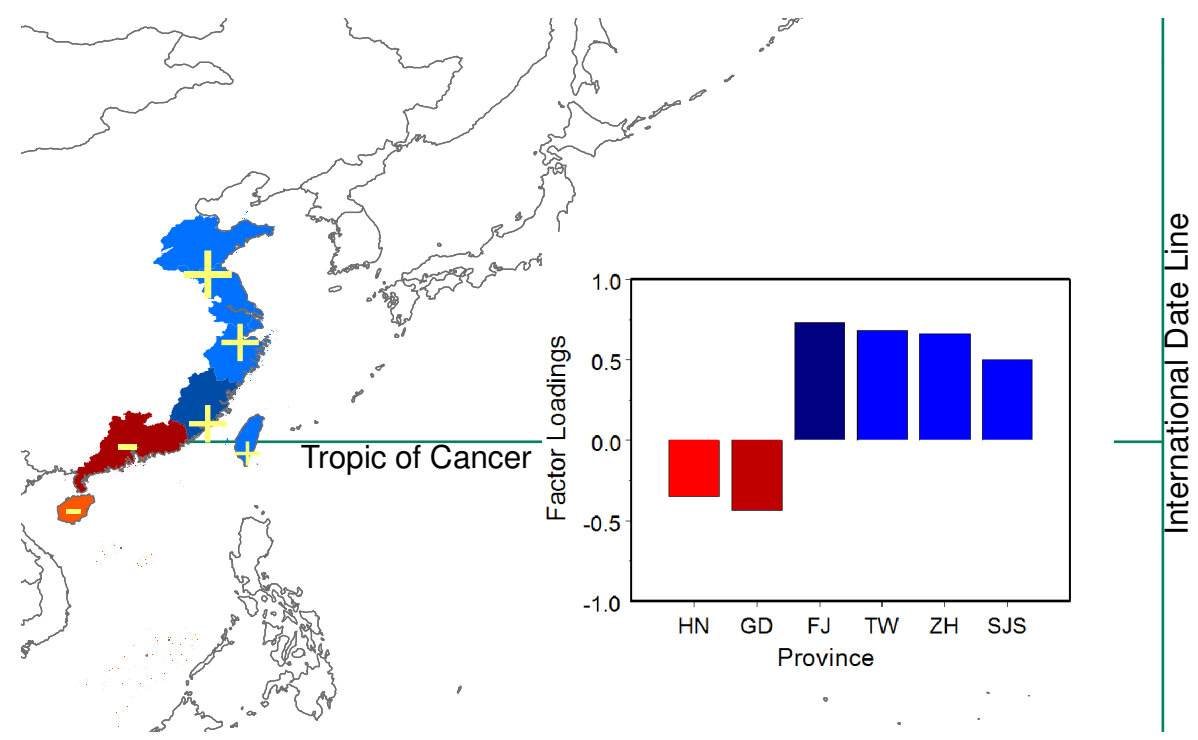

Fig. 6. Values of the factor loadings from a factor analysis model using a maximum likelihood method. HN: Hainan, GD: Guangdong, FJ: Fujian, TW: Taiwan, ZH: Zhejiang, SJS: Shanghai, Jiangsu, Shandong. The factor loading sign is plotted in the corresponding map region.

ized by the LI describes the north-south variation in typhoon landfalls. Years with straight-moving typhoons that influence southern China have a large negative LI and years with recurving typhoons that influence northern China have a large positive LI.

\subsection{Statistical Significance}

Since there are no direct methods to test the statistical significance of the factor-analysis results, we employ Monte Carlo simulations. Simulations are performed to test whether the north-south split in factor loadings could have occurred by chance. The annual frequency of storm occurrences in each province is randomized with respect to year. For example, in 1945 the relative frequency of Guangdong typhoons was 8 percent, but under a single randomization it is 13 percent. One can constrain all the rows and columns and simulate the possible combinations of counts and assign probabilities to them. This is based on work from Patefield (1981) which gives an efficient method of generating $r \times c$ tables with given row and column totals.
This is a multinomial sampling scheme where the frequencies are randomized but the marginal totals are preserved.

Here the relative frequencies of landfalls are randomized 1000 times. Samples are drawn from the conditional distribution of the table given the margins. Rows contain the annual basin totals and the columns are the annual province totals; an additional column is included that contains the sum of basin-wide activity that did not affect any province. An assumption is made that the number of storms in each year and the proportion of storms in the basin for each province is constant; only the relative frequency of landfalls per region changes for each simulation. From these assumptions we simulate the number of storms for each province for each year. For every simulation, we repeat the one-factor model and compute the intercept and slope of a regression of the loadings against the province order from north to south.

The slope from a regression of the loadings on latitude order (south to north) is +0.21 using the observed 


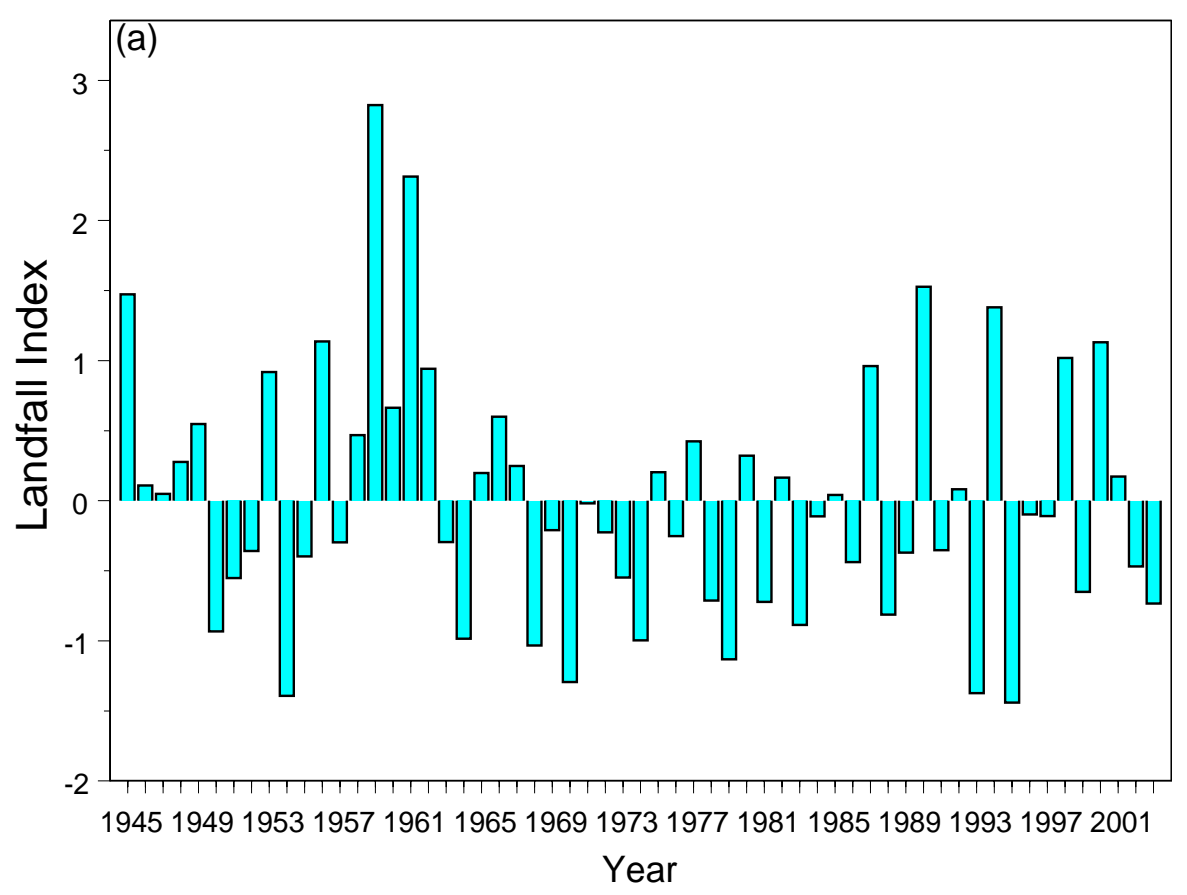

Fig. 7. (a) A landfall index (LI) obtained by linearly projecting the factor loadings from the factor analysis model onto the annual landfall frequencies using linear regression. Tracks of typhoons in (b) 1959 when the LI was large and positive, and in (c) 1995 when the LI was large and negative.

typhoon landfall frequencies. The null hypothesis is that the magnitude of the slope is zero, corresponding to the result that there is no relationship in landfall frequencies across the provinces. The number of samples in the simulation with an absolute value of the slope greater than or equal to 0.21 under the independence assumption is 6 , so the $p$-value is $6 / 1000=$ 0.006. Thus the null hypothesis that the magnitude of the slope is zero is rejected. The small $p$-value indicates that the observed north-south one-factor split does not occur at random.

\section{Relation of the Landfall Index to Climate Factors}

Results from the historical and modern records indicate a significant geographic variation in typhoon landfall frequency over China on an interannual basis. In years with above-normal landfall activity over Guangdong and Hainan, there are fewer storms over Fujian and provinces to the north. What causes this variation, and can it be explained by variations in atmospheric and oceanic variables?

As mentioned, the coherent north-south signal in China landfalls is expressed as a value for the LI each year. We now turn our attention to the possibility that a portion of the interannual variation in the LI can be statistically explained by variations in climate factors. However, we find little correlation between the LI and the SOI. The SOI is an indicator of the El
Niño-Southern Oscillation (ENSO). Here the SOI is averaged over the months of May through November. The Pearson's product-moment correlation coefficient $r[\mathrm{LI}, \mathrm{SOI}]=-0.12$. On the other hand, there is a weak correlation with the Pacific decadal oscillation (PDO), as measured by the PDOI. Here $r[\mathrm{LI}, \mathrm{PDO}]=-0.20$ using values averaged from May through November. The PDO is the dominant factor in monthly SST variability in the North Pacific (Mantua et al., 1997). During the warm phase of the PDO, there are cooler SSTs and higher SLPs over the northern Pacific. Although this relationship exists, it is not very strong, thus we are motivated to look at other climate signals.

It has been proposed by Liu et al. (2003) that variations in coastal typhoons might be related to regional climatological connections such as anomalous SST over the northwestern Pacific (north of $30^{\circ} \mathrm{N}$ ) during the typhoon summer and fluctuations in SLP patterns between western China and Mongolia. They noted that cooler SST in the northwestern Pacific, especially during the summer season, could displace the predominant storm tracks to the south. Ho et al. (2004) noted that SST increases in tropical regions of the WNP tend to coincide with SST decreases over the northern Pacific.

An annual index of the north-south SLP gradient between Mongolia and western China (SLPI) is made by taking SLP differences of the seasonal (MayNovember) averages for two regions bounded by $40^{\circ}-$ $60^{\circ} \mathrm{N}$ and $85^{\circ}-110^{\circ} \mathrm{E}$ (region 1 ) and $25^{\circ}-35^{\circ} \mathrm{N}$ and 

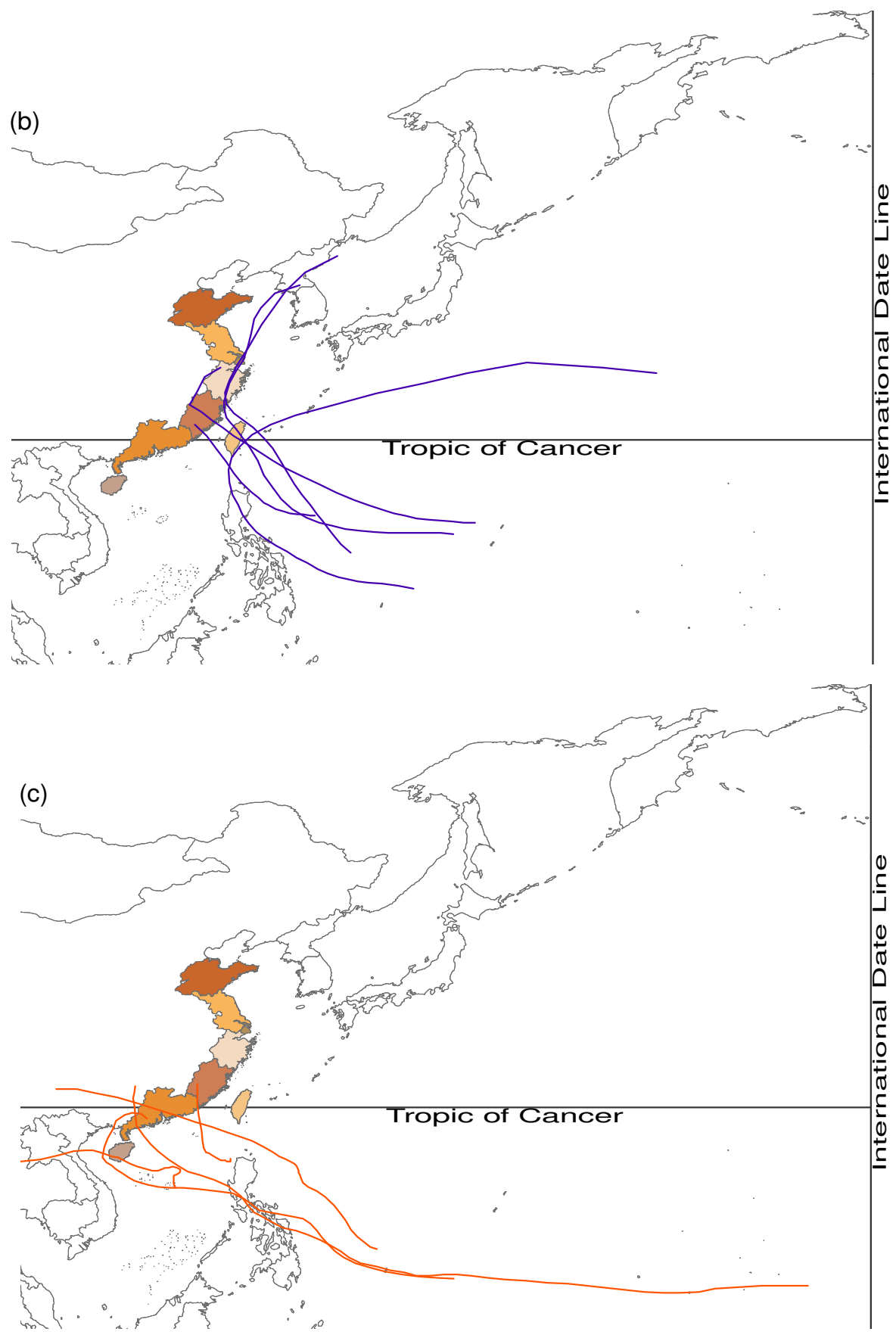

Fig. 7. (Continued.)

$75^{\circ}-100^{\circ} \mathrm{E}$ (region 2 ). These regions are based on differences in the large-scale steering flow between high and low LI years. The SLPI is the region 1 average minus the region 2 average. An annual index of SST (SSTI) is made by averaging over the months of June and August for the region bounded by $30^{\circ}-60^{\circ} \mathrm{N}$ and $150^{\circ}-180^{\circ} \mathrm{E}$. Values for the SLPI (SSTI) are in $\mathrm{hPa}$ $\left({ }^{\circ} \mathrm{C}\right)$.
The correlation between SLPI and LI ( $r$ [LI, SLPI $]$ ) is -0.43 and the correlation between SSTI and LI $(r[\mathrm{LI}, \mathrm{SSTI}])$ is +0.31 . Recall that negative values of the LI correspond to southern China landfalls, so a negative correlation indicates that Guangdong landfalls are associated with a strong pressure gradient (high values of SLPI) over western China. Further, the positive correlation between LI and SSTI indicates 
that a warmer ocean is also associated with southern landfalls. Scatter plots of these relationships are shown in Fig. 8. When the SLPI is high, indicating relative high pressures over Mongolia and low pressures over western China, the LI is low. This implies that when the SLP gradient over Mongolia is strong there is an increase in surface winds in the form of stronger easterlies over northern China which may inhibit typhoons from recurving, thereby increasing landfall activity over Guangdong Province. Also, when cooler SSTs occur over the northwestern Pacific (north of $30^{\circ} \mathrm{N}$ ) we see an increased likelihood of typhoons over southern China. Extensive and persistent SST anomalies produce substantial variations in atmospheric heating. We speculate that cooler SST over the NW Pacific can lead to increased middle and upper tropospheric troughiness over the northern Pacific through decreased turbulent transfer of sensible heat.

A linear regression model further quantifies these results. We regress the LI onto year, SLPI and SSTI. The multiple R-squared value indicates that $26 \%$ of the variability in the $\mathrm{LI}$ is explained by these two climate factors plus the trend. The $t$-value on the coefficient for SLPI (SSTI) is $-3.50(+2.46)$ providing a $p$-value of 0.001 (0.017). Diagnostic plots (not shown) give us no reason to suspect the underlying model assumptions. Thus both the SLPI and the SSTI appear to be individually important in explaining the variability in the landfall index. We note that the SSTI shows a significant decline over the 59-year period. Climatologically, typhoon tracks are determined by the genesis regions and steering flow. The strong pressure gradient indicates an enhanced subtropical high and stronger steering flow at atmospheric levels extending to at least $500 \mathrm{hPa}$. We examine the geopotential height gradient between region 1 and region 2 and find that the LI is significantly negatively correlated $r[\mathrm{LI}, 850(\mathrm{hPa})$ gradient $]=-0.35(p$-value $=0.024)$. Thus the differences in typhoon tracking that we find are due to differences in steering flow.

\section{Summary and Conclusions}

The variability of the typhoon landfall pattern in China is investigated using historical and modern records. The work is motivated by a recent hypothesis of an inverse relationship between the frequency of typhoons over northern China to those over Guangdong Province in the south (Liu et al., 2001; Elsner and Liu, 2003). The study makes use of the modern instrumental record of typhoons over the coastal provinces of China and documentary evidence of typhoons over Guangdong and Fujian. Indices for ENSO and the PDO are combined with regionally-averaged SLPs and SSTs to examine climate factors related to
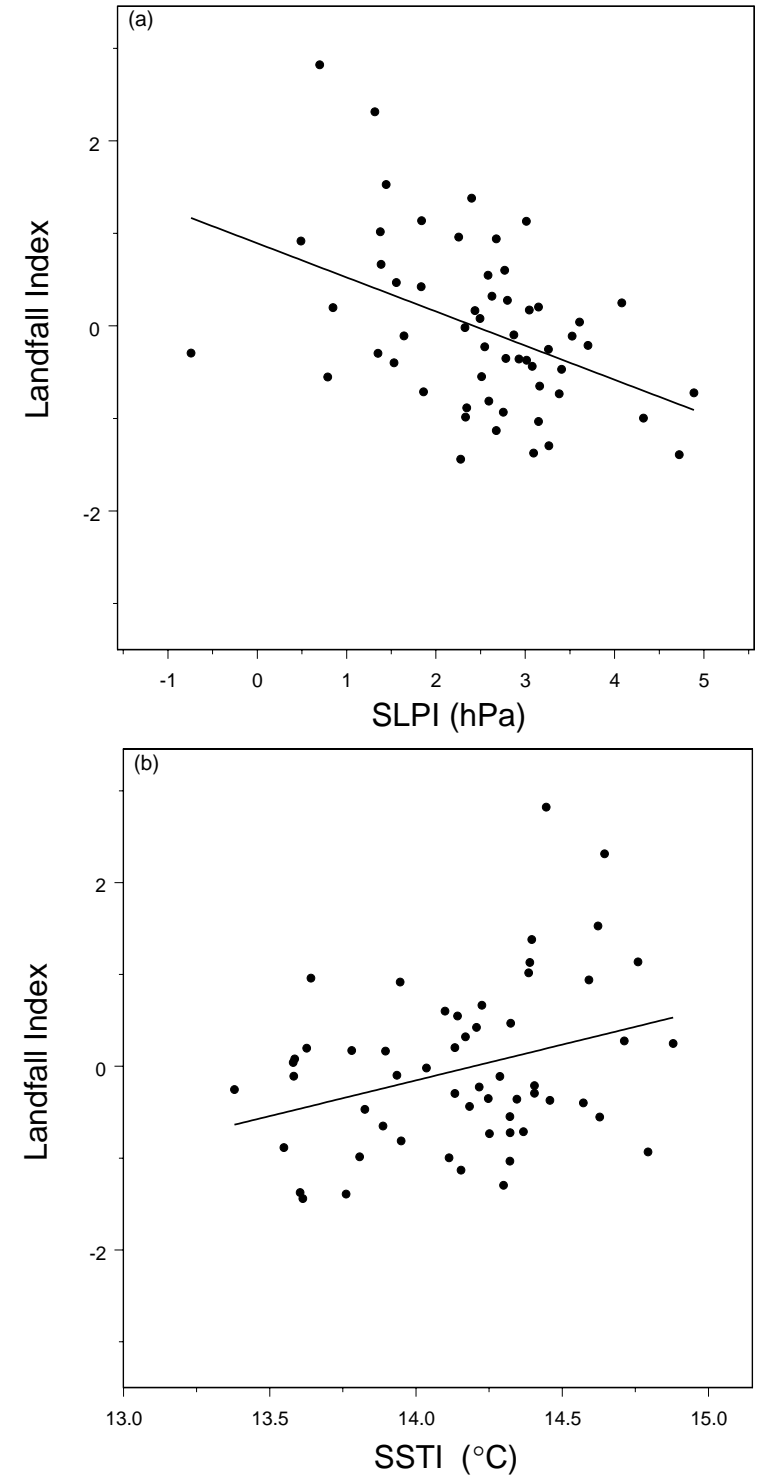

Fig. 8. (a) Scatter plot of the LI and the SLPI, and (b) scatter plot of the LI and SSTI. The solid line is the least-squares regression line.

the pattern of China landfalls. The originality of this work rests with the examination of both historical and modern landfall records and in the use of a factor model for identifying the dominant pattern of spatial landfall variability.

The historical records provide a hint at the important landfall pattern by showing a statistically significant negative correlation between the frequency of tropical cyclone landfalls over Guangdong and Fujian. When tropical cyclone activity over Guangdong is high (low), it tends to be low (high) over Fujian. The relationship is examined using correlation, conditional probabilities, and log-linear regression. The dominant landfall pattern is identified in the modern records of typhoon counts in coastal provinces using a factor 
analysis model. The model delineates the southern provinces of Guangdong and Hainan from the northern provinces of Fujian, Taiwan, Zhejiang, Shanghai, Jiangsu, and Shandong. When typhoon activity is high over the southern provinces, it tends to be low over the northern provinces. This result is new and provides a way to examine climate influences on geographic variations in typhoon activity. The statistical significance of the factor analysis model is tested using Monte Carlo simulations. A landfall index (LI) of annual activity representing the degree to which each year follows this pattern of activity is used to identify correlated climate variables.

The relationship between the dominant spatial pattern of China landfalls, as described by the LI, and climate is first examined using indices for ENSO and the PDO. Although the SOI is not linearly related to the LI, there is a weak relationship with the PDO. Examination of additional variables that might explain the landfall pattern indicates that a north-south SLP gradient between western China and Mongolia might be used as a predictor of regional typhoon activity. When the SLP gradient features relatively high pressures over Mongolia and low pressures over western China, typhoons are more likely to track westward toward southern China. In contrast, when the SLP gradient weakens, recurving typhoons are more likely to visit the northern provinces of China.

Additionally, ocean surface temperatures over the higher latitudes of the northwestern Pacific are correlated with the pattern of typhoon landfalls. When temperatures are cooler than normal, typhoons are relatively more likely over southern China. A linear regression model that includes sea level pressure differences between Mongolia and western China and SST over the northwestern Pacific explains $26 \%$ of the interannual variability of the LI. A stronger than normal surface pressure gradient increases the easterly wind flow over China forcing the fledgling storms to track westward toward the southern coast. Moreover, colder water over the WNP shifts the subtropical high pressure farther to the west and south, thus keeping tropical cyclones over lower latitudes and tracking them toward Hong Kong. These results are consistent with the speculation put forth in Liu et al. (2003) that typhoons are more abundant across Guangdong when the climate is drier and windier in northern and central China.

The major conclusions of this study are:

1. Historical typhoon records from the Guangdong and Fujian provinces of China dating back to 1600 are inversely correlated on the annual timescale.

2. A factor model applied to modern typhoon counts in the coastal provinces of China indicates a north-south split in activity, with the split occurring between Guangdong and Fujian.

3. The factor model is statistically significant against a null hypothesis of a random distribution of landfalls.

4. The factor scores provide a landfall index (LI) of the dominant geographical pattern in China landfall activity from year to year.

5. The LI is not significantly related to either the SOI or the PDO.

6. The north-south SLP gradient over central Asia and SSTs over the higher latitudes of the northwestern Pacific Ocean are significantly related to the LI on an annual basis, although the variance explained is only $26 \%$.

The study can be improved. For example, it would be interesting to examine the geographic pattern of strong typhoons over China. It is likely to be similar to that of the general typhoon pattern, but it might be more pronounced. More importantly, it would be revealing to examine the results of a factor model applied to the historical records. This would allow a more detailed comparison of the historical and modern records. Unfortunately, typhoon counts for provinces other than Guangdong and Fujian are unavailable at this time. Finally, a closer examination of other climate variables might reveal additional relationships with the typhoon landfall pattern.

Acknowledgments. Partial support for this study was provided by the U. S. National Science Foundation (BCS-0213980). The views expressed herein are those of the authors and do not reflect those of the funding agency.

\section{REFERENCES}

Bove, M. C., J. B. Elsner, C. W. Landsea, X. Niu, and J. J. O'Brien, 1998:: Effect of El Niño on U.S. landfalling hurricanes, revisited. Bull. Amer. Meteor. Soc., 79, $2477-2482$

Chan, J. C., 1985: Tropical cyclone activity in the NW Pacific in relation to the ENSO phenomenon. Mon. Wea. Rev., 113, 599-606.

Chan, J. C., 1994: Prediction of the interannual variations of tropical cyclone movement over regions of the western North Pacific. International Journal of Climatology, 14, 527-538.

Chan, J. C. L., J. E. Shi, and C. M. Lam , 1998: Seasonal forecasting of tropical cyclone activity over the western North Pacific and South China. Wea. Forecasting, 13, 997-1004.

Chan, J. C., and J.-E. Shi, 2000: Frequency of typhoon landfall over Guangdong province of China during the period of 1470-1931. International Journal of Climatology, 20, 183-190. 
China Daily, 2003: "Typhoon Nepartak Leaves Hundreds Homeless." China Daily 21 November 2003. [Available online from http://www.china.org.cn/english/China/80563.htm.]

Chen, T., S. P. Weng, N. Yamazaki, and S. Kiehne, 1998: Interannual variation in the tropical cyclone formation over the western North Pacific. Mon. Wea. Rev., 126, 1080-1090.

DeMaria, M., J. A. Knaff, and B. H. Connell, 2001: A tropical cyclone genesis parameter for the tropical Atlantic. Wea. Forecasting, 16, 219-233.

Elsner, J. B., and A. B. Kara, 1999: Hurricanes of the North Atlantic: Climate and Society. Oxford University Press, 512pp.

Elsner, J. B., K. B. Liu, and B. Kocher, 2000: Spatial variations in major U. S. hurricane activity: Statistics and a physical mechanism. J. Climate, 13, 2293-2305.

Elsner, J. B., and Liu, K.-b., 2003: Examining the ENSOTyphoon hypothesis. Climate Research, 25, 43-54.

Emanuel, K. A., 1988: Towards a general theory of hurricanes. Amer. Sci., 13, 2293-2305.

Gray, W. M., 1968: Global view of the origin of tropical disturbances and storms. Mon. Wea. Rev., 96, 669700 .

Gray, W. M., 1979: Hurricanes: Their formation, structure, and likely role in the tropical circulation. $M e$ teorology over the Tropical Oceans, D. B. Shaw, Ed., Royal Meteorology Society, London, 155-218.

Ho, C. H., J. J. Baik, J. H. Kim, D. Y. Gong, and C. H. Sui, 2004: Interdecadal changes in summertime typhoon tracks. J. Climate, 17, 1767-1776.

Kentang, L. E., 2000: An analysis of the recent servere storm surge disaster events in China. Natural Hazards, 21, 215-223.

Lander, M. A., 1994: An exploratory analysis of the relationship between tropical storm formation in the western North Pacific and ENSO. Mon. Wea. Rev., 122, 636-651.

Lander, M. A., 1996: Specific tropical cyclone track types and unusual tropical cyclone motions associated with a reverse oriented monsoon trough in the western North Pacific. Wea. Forecasting, 11, 170-187.
Lander, M. A. and C. P. Guard, 1998: A look at global tropical cyclone activity during 1995: Contrasting high Atlantic activity with low activity in other basins. Mon. Wea. Rev., 126, 1163-1173.

Louie, K-S., and K-B Liu, 2003: Earliest historical records of typhoons in China. Journal of Historical Geography, 29, 299-316.

Liu, K. B, C. Shen, and K. S. Louie, 2003: A 1000-year history of typhoon landfalls in Guangdong, southern China, reconstructed from Chinese historical documentary records. Annals of the Association of American Geographers, 91, 453-464.

Mantua, N. J., S. R. Hare, Y. Zhang, J. M. Wallace, and R. C. Francis, 1997: A Pacific interdecadal climate oscillation with impacts on salmon production. Bull. Amer. Meteor. Soc., 78, 1069-1079.

Molinari, J., and D. Vollaro, 1989: External influences on hurricane intensity. Part I: Outflow layer eddy angular momentum fluxes. J. Atmos. Sci., 46, 1093-1105.

Parisi, F., and R. Lund, 2000: Seasonality and return periods of landfalling Atlantic basin hurricanes. Australian and New Zealand Journal of Statistics, 42, 271-282.

Patefield, W. M., 1981: Algorithm AS159. An efficient method of generating $\mathrm{r} \times \mathrm{c}$ tables with given row and column totals. Applied Statistics, 30, 91-97.

Saunders, M. A., Chandler, R. E., C. J. Merchant, and F. P. Roberts, 2000: Atlantic hurricanes and NW Pacific typhoons: ENSO spatial impacts on occurrence and landfall. Geophys. Res. Lett., 27, 1147-1150.

Solow, A. R., and L. Moore, 2000: Testing for a trend in a partially incomplete hurricane record. J. Climate, 13, 3696-3699.

Wang, B., and C. L. Chan, 2002: How strong ENSO events affect tropical storm activity over the western North Pacific. J. Climate, 15, 1643-1658.

Wu, G., and N. C. Lau , 1992: A GCM simulation of the relationship between tropical storm formation and ENSO. Mon. Wea. Rev., 120, 958-977.

Wu, M. C., W. L. Chang, and W. M. Leung, 2004: Impacts of El Niño-Southern Oscillation events on tropical cyclone landfalling activity in the western North Pacific. J. Climate, 17, 1419-1428. 